DOI 10. 18307/2021. 0611

(c) 2021 by Journal of Lake Sciences

\title{
淮南采煤沉陷区积水水文地球化学及氢氧稳定同位素特征"
}

\author{
查君珍 ${ }^{1}$, 姜春露 $^{1,2 * *}$, 陈 星 $^{1}$, 安士凯 $^{3}$, , 郑刘根 $^{1}$, 陈永春 $^{3}$ \\ ( 1 : 安徽大学资源与环境工程学院, 安徽省矿山生态修复工程实验室, 合肥 230601) \\ (2: 中国矿业大学 (北京) 地球科学与测绘工程学院,北京 100083) \\ (3: 煤矿生态环境保护国家工程实验室,淮南 232001)
}

\begin{abstract}
摘 要: 以安徽淮南采煤沉陷积水为研究对象,通过样品采集与测试, 研究不同沉陷年限及类型积水水文地球化学和氢 氧稳定同位素组成特征及影响因素. 结果表明: (1) 研究区水化学类型主要为 $\mathrm{Cl}-\mathrm{Na} 、 \mathrm{HCO}_{3} \cdot \mathrm{Cl}-\mathrm{Na}$ 型, 沉陷积水中常量离 子主要来源于蒸发岩溶解和硅酸盐风化, 受蒸发作用和人为活动的影响明显, 水化学组成随沉陷时间和类型变化不大. (2) 淮南大气降水线方程为: $\delta \mathrm{D}=8.85 \delta^{18} \mathrm{O}+18.73$, 沉陷区积水氢氧稳定同位素值在淮南大气降水线右下方依次分布并接 近降水线, 表明沉陷积水主要来源于大气降水. (3) 在降水稀释、水体蒸发及地下水补给的作用下, 随着沉陷年限的增加, 积水中重同位素越来越贫化,同一年限不同类型的积水同位素值变化较小.
\end{abstract}

关键词: 淮南;沉陷积水;水化学;氢氧稳定同位素

\section{Hydrogeochemistry and hydrogen and oxygen stable isotope characteristics of water in Huainan subsidence areas*}

Zha Junzhen ${ }^{1}$, Jiang Chunlu ${ }^{1,2 * *}$, Chen Xing ${ }^{1}$, An Shikai ${ }^{3}$, Zheng Liugen ${ }^{1}$ \& Chen Yongchun ${ }^{3}$

(1: School of Resource and Environmental Engineering, Anhui Province Engineering Laboratory for Mine Ecological Remediation, Anhui University, Hefei 230601, P.R.China)

(2: College of Geoscience and Surveysing Engineering, China University of Mining \& Technology, Beijing 100083, P.R.China)

(3: National Engineering Laboratory for Protection of Coal Mine Eco-environment, Huainan 232001, P.R. China)

Abstract: Taking the coal mining subsidence water in Huainan, Anhui Province as the research object, through sample collection and testing, the hydrogeochemistry, hydrogen and oxygen stable isotopic composition characteristics and influencing factors of different subsidence years and types of water are studied. The results show that: (1) The main types of water chemistry in the study area are $\mathrm{Cl}-\mathrm{Na}$ and $\mathrm{HCO}_{3} \cdot \mathrm{Cl}-\mathrm{Na}$. The major ions in the sedimentation water mainly come from evaporite dissolution and silicate weathering, and are affected by evaporation and human activities. Obviously, the chemical composition of water does not change much with the time and type of subsidence. (2) The Huainan atmospheric precipitation line equation is: $\delta \mathrm{D}=8.85 \delta^{18} \mathrm{O}+18.73$. The hydrogen and oxygen stable isotopic values of the accumulated water in the subsidence area are distributed in sequence at the lower right of the Huainan atmospheric precipitation line and are close to the precipitation line, indicating that the subsided water mainly comes from atmospheric precipitation. (3) Under the effects of precipitation dilution, water evaporation, and groundwater replenishment, with the increase of the subsidence period, the heavy isotopes of the accumulated water become more and more depleted. The isotopic values of different types of accumulated water of the same age have little change, which is affected by the isotopes.

Keywords: Huainan; water in subsidence lake; hydrochemistry; stable isotopes of hydrogen and oxygen

* 2021-02-08 收稿; 2021-04-08 收修改稿.

国家自然科学基金项目 (41602310) 和中国博士后科学基金项目(2017M611044) 联合资助.

** 通信作者;E-mail:ahuclj@ ahu.edu.cn. 
在我国东部,煤炭开采活动形成大面积沉陷区. 据不完全统计, 两淮矿区目前已形成超过 $600 \mathrm{~km}^{2}$ 沉陷 区, 积水面积占比达到 $50 \% \sim 70 \%^{[1]}$. 随着矿区地质环境治理与生态文明建设的全面推进, 人们提出了建设 平原水库、湿地公园等多种沉陷区水资源利用模式 ${ }^{[2-3]}$, 营造湿地生态系统, 发挥沉陷水域蓄滞洪涝水、调蓄 水资源的作用, 改善区域生态环境, 丰富景观多样性和生物多样性, 最大程度降低煤炭开采沉陷的不利影响. 此时,沉陷区积水来源、构成及其变化等水循环要素的合理评估是采煤沉陷区水资源可持续利用的理论依 据和重要前提. 因此, 开展采煤沉陷区积水水化学特征及循环转化研究具有重要的理论意义和重大现实 需求.

以往已有许多学者关注并研究沉陷区积水, 主要集中在水环境质量及评价等方面 ${ }^{[4-7]}$, 关注沉陷区积水 来源、蒸发等水循环要素较少. 氢氧稳定同位素作为水分子的组成部分, 能够很好反映天然水行为,对环境 变化能够做出敏感反映并有效地追踪这些变化, 是水循环过程的理想示踪剂, 在水循环研究方面具有明显 的优势. 氢氧稳定同位素既可以从区域尺度和局地尺度解析水汽和水循环过程、示踪湖水与河水的混合情 况, 确定河流补给湖泊的路径及季节性变化 ${ }^{[8-9]}$, 也可以定量评估平原湖泊补给量和蒸发量、量化地下水对 地表河流的补给贡献, 以及研究梯级大坝对河流水循环影响的长时间累积效应 ${ }^{[10-12]}$. 这些研究主要以自然 条件下形成的河流、湖泊为研究对象, 关于人工开采条件下形成的采煤沉陷区积水的氢氧稳定同位素研究 较少. 张否等 ${ }^{[13]}$ 通过氢氧稳定同位素研究, 指出淮南采煤沉陷区积水的主要来源是大气降水. 但其仅限于 定性分析, 未涉及沉陷时间和类型等影响因素分析. 人工开采沉陷湖泊与天然湖泊不同, 积水盆地随开采时 间变化,这将对沉陷区积水水化学和氢氧稳定同位素组成分布特征产生重要影响.

基于此,本研究以淮南不同形成时间和沉陷类型的沉陷积水为研究对象, 通过不同水体样品采集与测 试,采用水化学结合氢氧稳定同位素方法, 分析研究区积水的主要离子含量、氢氧稳定同位素组成等, 以期 阐明不同年限和类型的沉陷积水水化学类型及主要影响因素, 揭示沉陷区积水氢氧稳定同位素组成分布特 征. 研究成果可为采煤沉陷区水资源综合开发利用提供理论科学依据.

\section{1 研究区概况}

研究区位于安徽省淮南市, 地处亚热带湿润季风气候区, 多年平均降水量约 $926 \mathrm{~mm}$, 年平均蒸发量为 $1442.9 \mathrm{~mm}^{[14]}$. 区域内四季分明,降雨多集中在夏季, 主导风向为东南风和东北风. 矿区内地表水系发育, 主 要有西淝河、茨淮新河、济河、泥河和淮河干流, 流向由西北向东南方向. 研究区新生界松散含水层从上至下 分为 4 个含水层组, 其中上部第一含水层从地面至第一隔水层, 平均厚 $27 \mathrm{~m}$, 岩性以粉细砂为主, 属潜水一 弱承压水, 富水性中等一强,多年水位平均埋深 1 3 m, 季节变化明显.

矿区东西长约 $70 \mathrm{~km}$, 南北宽约 $25 \mathrm{~km}$, 面积约为 $1500 \mathrm{~km}^{2[15]}$. 研究区地处淮河中游冲积平原区内, 属华 北陆块南缘的徐淮地块, 整体为 NWW 向展布的对冲式断禇构造带, 淮南复向斜为主要地质构造. 区域构造 和新构造运动控制水文地质条件.

顾桥矿 2006 年投产,沉陷时间 10 余年,沉陷面积约 $12.63 \mathrm{~km}^{2}$, 与地表水系无联系,南侧为矿井工业广 场, 西南侧为煤研石堆放场. 潘二矿 1992 年投产, 沉陷时间 20 余年, 沉陷面积约 $9.21 \mathrm{~km}^{2}$, 距泥河约 $2 \mathrm{~km}$, 属于封闭性水域,水域有渔业养殖活动. 新庄孜矿位于淮河以南, 部分区域沉陷时间在 30 余年, 水域面积约 $0.24 \mathrm{~km}^{2}$, 与地表水系无连通, 属于封闭性水域. 潘一矿 1983 年投产, 沉陷时间 30 余年,沉陷区水域面积约 $18.82 \mathrm{~km}^{2}$, 与地表水系连通,泥河自西向东贯穿潘一沉陷区 ${ }^{[16]}$, 属于开放型水域.

\section{2 样品采集与测试分析}

根据沉陷区沉陷年限及类型的不同, 采集 4 个沉陷区积水、大气降水、泥河河水及地下水. 共采集水样 59 个,其中沉陷积水 23 个、大气降水 22 个、河水 6 个、地下水 8 个. 具体的采样点分布见图 1.

根据降水情况, 于 2017 年 3-12 月在淮南煤矿生态环境保护工程实验采集大气降水样品. 在采样点 (无林空旷地) 内随机放置标准采集器 (500 $\mathrm{mL}$ 塑料瓶上放置直径为 $10 \mathrm{~cm}$ 的漏斗, 下端与集水瓶连接, 漏斗 内放置乒乓球防止雨水蒸发), 水样采集后立即装人采样瓶充分混合, 并迅速用 Parafilm 封口膜密封瓶口, 所 有收集的降水样品置于 $0 \sim 5^{\circ} \mathrm{C}$ 冰箱中保存. 


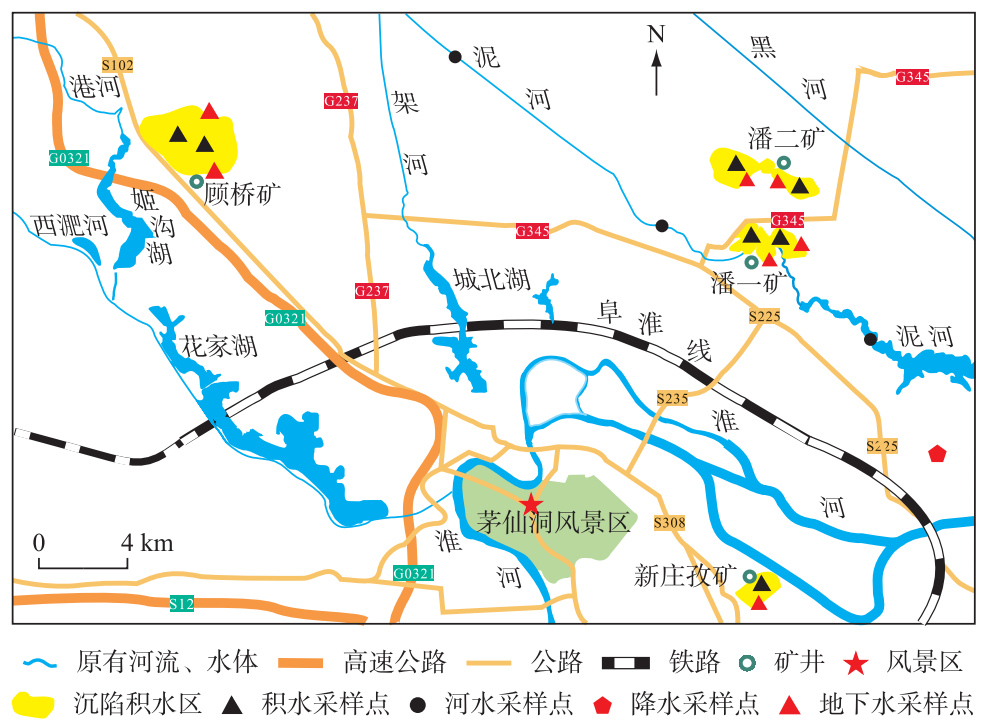

图 1 采样点分布

Fig.1 Distribution of sampling points

沉陷区积水和河水水样用预先清洗干净的 $500 \mathrm{~mL}$ 聚乙烯瓶采集. 取样前用原水样润洗样瓶 3 5 次, 采 样时应快速装满样品瓶, 保证瓶内无气泡, 密封低温保存. 在野外现场用 $\mathrm{pH}$ 仪 (WTWoxi315i) 和便携式水质 检测仪 (WTWoxi315i) 对温度、 $\mathrm{pH}$ 、电导率及氧化还原电位等基本水质参数进行现场测定. 用于分析阳离子 的水样加 $5 \%$ 的 $\mathrm{HNO}_{3}$, 调节水样 $\mathrm{pH}<2$, 所得数据经过校正后使用. 用于分析氢氧稳定同位素的水样单独封 装,密封保存.

阴离子 $\left(\mathrm{SO}_{4}^{2-} 、 \mathrm{Cl}^{-}\right)$的浓度使用离子色谱仪 ( ICS-1500) 测定, $\mathrm{HCO}_{3}^{-}$浓度采用滴定法进行测定; 阳离子浓 度使用电感耦合等离子发射光谱仪 (ICR-AES, IRIS Intrepid II XSP 型) 进行测定. 水体总溶解固体 (TDS) 浓 度采用阴、阳离子浓度之和减去 $1 / 2 \mathrm{HCO}_{3}^{-}$浓度方法计算. 氢氧稳定同位素在中国科学院地球环境研究所同 位素实验室进行, 使用液态水和水汽同位素分析仪 (Picarro, L2130-i) 测试. 仪器的测试精度 $\delta^{18} \mathrm{O}$ 优于 $\pm 0.1 \% \circ, \delta \mathrm{D}$ 优于 $\pm 0.5 \%$, 同位素的测试结果均以相对于 V-SMOW 的千分偏差值表示 ${ }^{[17]}$. 所有样品常量离子 含量均通过电荷守恒检验 ( 误差 $<5 \%$ ). 试验所用器血均用 $1: 10$ 的 $\mathrm{HNO}_{3}$ 浸泡 $24 \mathrm{~h}$ 后用纯水润洗、烘干后使 用. 本研究所用平均气温、相对湿度及降雨量等气象要素资料来源于国家气象信息中心.

\section{3 结果与分析}

\section{1 水文地球化学特征}

3.1 .1 主要离子浓度特征 研究区顾桥、潘二、新庄孜及潘一矿沉陷区水体主要离子浓度详见表 1 , 大气降 水、河水未测定常规离子,故不列举出. 由表 1 可看出,不同沉陷区水体离子浓度变化不大. 顾桥、潘二、新庄 孜及潘一矿沉陷区水体 $\mathrm{pH}$ 变化范围为 7.63 9.50, 均值分别为 8.84、8.33、8.09 和 8.43, 水样呈弱碱性. TDS 浓度较低且变化范围小, 在 4 个沉陷区中均值分别为 $480.5 、 427.8 、 638.96$ 和 $438.6 \mathrm{mg} / \mathrm{L}$, 属于低矿化度水的 类型. 4 个沉陷区水体阴阳离子平均浓度大小顺序一致, 阳离子表现为 $\mathrm{Na}^{+}>\mathrm{Ca}^{2+}>\mathrm{Mg}^{2+}>\mathrm{K}^{+}, \mathrm{Na}^{+}$为优势阳离 子, 在 4 个沉陷区中分别占总阳离子浓度的 $81.02 \% 、 73.57 \% 、 74.35 \%$ 和 $76.71 \%$. 阴离子平均浓度大小顺序 为 $\mathrm{HCO}_{3}^{-}>\mathrm{Cl}^{-}>\mathrm{SO}_{4}^{2-}, \mathrm{HCO}_{3}^{-}$为优势阴离子, 在 4 个沉陷区中分别占总阴离子浓度的 $56.81 \% 、 64.22 \% 、 54.49 \%$ 和 $54.45 \%$.

3.1 .2 水化学类型及影响因素 由于地表水组分较为复杂, 常用 Piper 三线图来分析水化学类型, 反映水体 主要离子组成及特征, 并判辨其控制端元 ${ }^{[18]}$. 将研究区水样的主要离子组成绘制在 Piper 三线图内 (图 2). 在阳离子三角形中, 4 个沉陷积水都位于区域 4 , 靠近 $\mathrm{Na}^{+}+\mathrm{K}^{+}$端元, 属于钠钾水化学类型, $\mathrm{Na}^{+}$为优势阳离 
表 1 沉陷积水水化学和同位素组成

Tab.1 Hydrochemical and isotopic composition of subsidence lake water

\begin{tabular}{|c|c|c|c|c|c|c|c|c|c|c|c|c|c|}
\hline 水样类型 & 统计值 & $\mathrm{pH}$ & $\begin{array}{c}\mathrm{Ca}^{+} / \\
(\mathrm{mg} / \mathrm{L})\end{array}$ & $\begin{array}{l}\mathrm{Mg}^{2+} / \\
(\mathrm{mg} / \mathrm{L})\end{array}$ & $\begin{array}{c}\mathrm{Na}^{+} / \\
(\mathrm{mg} / \mathrm{L})\end{array}$ & $\begin{array}{c}\mathrm{K}^{+} / \\
(\mathrm{mg} / \mathrm{L})\end{array}$ & $\begin{array}{l}\mathrm{HCO}_{3}^{-} / \\
(\mathrm{mg} / \mathrm{L})\end{array}$ & $\begin{array}{c}\mathrm{Cl}^{-} / \\
(\mathrm{mg} / \mathrm{L})\end{array}$ & $\begin{array}{l}\mathrm{SO}_{4}^{2-} / \\
(\mathrm{mg} / \mathrm{L})\end{array}$ & $\begin{array}{c}\text { TDS/ } \\
(\mathrm{mg} / \mathrm{L})\end{array}$ & $\begin{array}{c}\delta^{18} \mathrm{O} / \\
\% 0\end{array}$ & $\begin{array}{c}\delta \mathrm{D} / \\
\% 0\end{array}$ & $\begin{array}{l}d / \\
\% 0\end{array}$ \\
\hline 顾桥矿 & 最大值 & 9.50 & 41.40 & 9.11 & 359.25 & 6.52 & 596.32 & 178.11 & 104.03 & 857.9 & -1.71 & -17.02 & -1.44 \\
\hline \multirow[t]{4}{*}{ 沉陷区积水 } & 最小值 & 8.13 & 12.57 & 3.84 & 90.30 & 1.98 & 90.54 & 38.09 & 36.97 & 293.23 & -2.73 & -24.20 & -3.82 \\
\hline & 均值 & 8.84 & 25.20 & 6.25 & 151.00 & 3.93 & 238.43 & 111.68 & 69.58 & 480.48 & -2.20 & -20.48 & -2.88 \\
\hline & 标准差 & 0.57 & 8.93 & 2.00 & 90.99 & 1.55 & 164.93 & 40.94 & 20.41 & 178.57 & 0.37 & 2.59 & 0.72 \\
\hline & 变异系数 & 0.06 & 0.35 & 0.35 & 0.60 & 0.39 & 0.69 & 0.37 & 0.29 & 0.37 & -0.17 & -0.13 & -0.25 \\
\hline 潘二矿 & 最大值 & 9.00 & 57.00 & 13.70 & 152.10 & 8.72 & 396.51 & 99.41 & 75.91 & 450.24 & -3.12 & -26.14 & 2.81 \\
\hline \multirow[t]{4}{*}{ 沉陷区积水 } & 最小值 & 7.98 & 16.17 & 4.83 & 103.40 & 3.45 & 201.36 & 75.14 & 34.98 & 397.96 & -5.34 & -43.33 & -1.40 \\
\hline & 均值 & 8.33 & 30.24 & 8.07 & 122.23 & 5.61 & 251.70 & 85.96 & 54.26 & 427.82 & -4.56 & -36.62 & 1.51 \\
\hline & 标准差 & 0.41 & 16.09 & 4.07 & 19.75 & 1.92 & 100.73 & 12.35 & 14.90 & 21.80 & 0.86 & 6.31 & 0.62 \\
\hline & 变异系数 & 0.05 & 0.53 & 0.50 & 0.16 & 0.34 & 0.40 & 0.14 & 0.27 & 0.05 & -0.19 & -0.17 & 0.40 \\
\hline 新庄孜矿 & 最大值 & 8.45 & 44.17 & 10.95 & 196.25 & 13.25 & 356.32 & 151.22 & 90.96 & 826.14 & -6.71 & -52.00 & 3.12 \\
\hline \multirow[t]{4}{*}{ 沉陷区积水 } & 最小值 & 7.63 & 21.59 & 6.91 & 95.35 & 5.43 & 189.65 & 59.53 & 77.07 & 449.17 & -7.43 & -53.16 & 1.41 \\
\hline & 均值 & 8.09 & 32.00 & 9.28 & 145.8 & 9.01 & 251.63 & 123.80 & 86.38 & 638.96 & -6.95 & -53.00 & 2.60 \\
\hline & 标准差 & 0.34 & 9.30 & 1.82 & 44.06 & 3.88 & 77.53 & 30.54 & 6.30 & 192.53 & 0.31 & 1.41 & 1.34 \\
\hline & 变异系数 & 0.04 & 0.28 & 0.20 & 0.30 & 0.43 & 0.31 & 0.25 & 0.07 & 0.30 & -0.04 & -0.03 & 0.51 \\
\hline 潘一矿 & 最大值 & 8.91 & 30.71 & 14.31 & 141.3 & 8.51 & 305.94 & 123.94 & 82.8 & 469.17 & -5.94 & -44.04 & 3.22 \\
\hline \multirow[t]{4}{*}{ 沉陷区积水 } & 最小值 & 8.06 & 17.87 & 5.79 & 117.49 & 6.00 & 112.05 & 81.83 & 36.35 & 400.79 & -7.61 & -58.10 & 1.04 \\
\hline & 均值 & 8.43 & 22.35 & 8.89 & 126.35 & 7.13 & 200.29 & 103.08 & 64.45 & 438.61 & -6.53 & -49.83 & 2.43 \\
\hline & 标准差 & 0.38 & 6.16 & 3.90 & 8.40 & 0.96 & 78.64 & 18.09 & 21.94 & 30.04 & 0.63 & 4.83 & 0.84 \\
\hline & 变异系数 & 0.05 & 0.28 & 0.44 & 0.07 & 0.13 & 0.39 & 0.18 & 0.34 & 0.07 & -0.10 & -0.10 & 0.35 \\
\hline
\end{tabular}

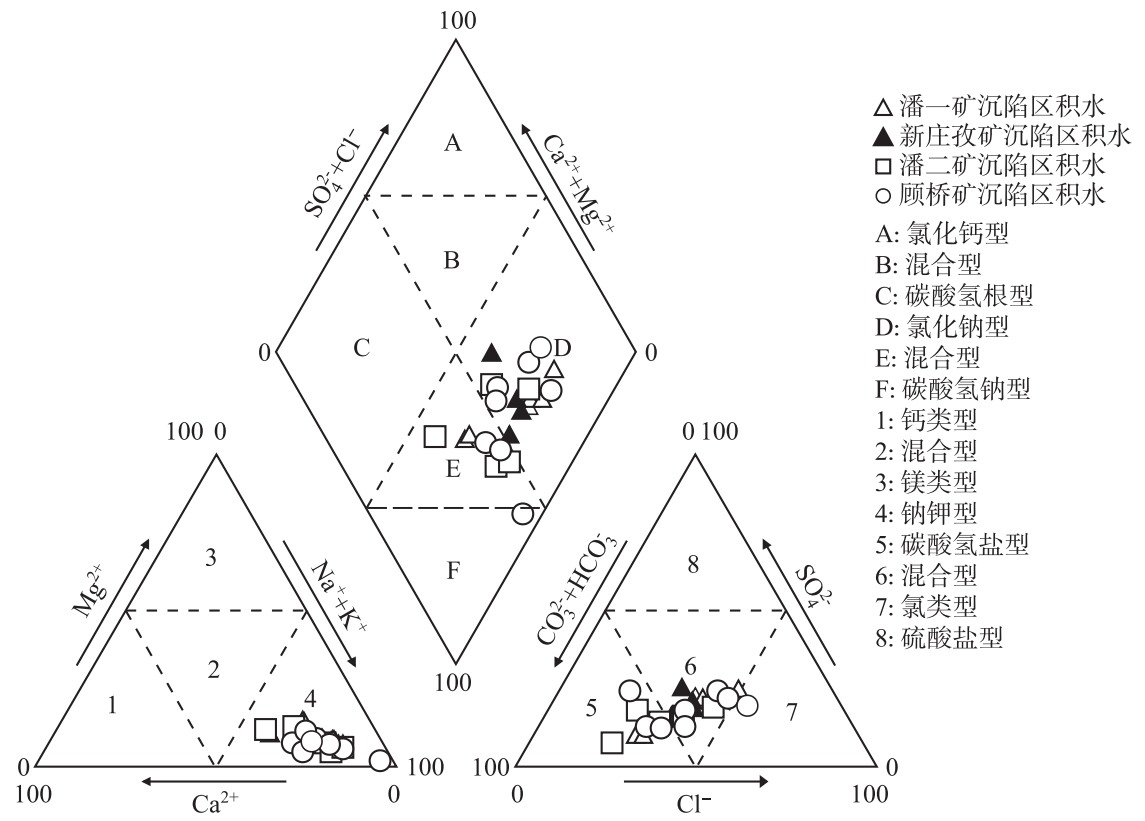

图 2 沉陷积水 Piper 三线图

Fig.2 Piper three-line diagram of subsidence lake water 
子,阳离子组分无明显变化. 在阴离子三角形中, 顾桥矿沉陷积水位于区域 $5 、 6$ 和区域 7 , 属于碳酸氢盐型、 氯类型及混合型, $\mathrm{HCO}_{3}^{-} 、 \mathrm{Cl}^{-}$及 $\mathrm{SO}_{4}^{2-}$ 分别占阴离子总量的 $25 \% \sim 60 \% 、 30 \% \sim 65 \%$ 和 $15 \% \sim 35 \%$. 潘二矿沉陷积 水位于区域 5 和 6 , 为碳酸氢盐型和混合型, $\mathrm{HCO}_{3}^{-} 、 \mathrm{Cl}^{-}$及 $\mathrm{SO}_{4}^{2-}$ 分别占 $40 \% \sim 80 \% 、 25 \% \sim 50 \%$ 和 $4 \% \sim 20 \%$. 新 庄孜矿沉陷积水位于区域 6, $\mathrm{HCO}_{3}^{-} 、 \mathrm{Cl}^{-}$及 $\mathrm{SO}_{4}^{2-}$ 分别占 $45 \% \sim 50 \% 、 40 \% \sim 48 \%$ 和 $18 \% \sim 32 \%$. 潘一矿沉陷积水 位于区域 5 和 $6, \mathrm{HCO}_{3}^{-} 、 \mathrm{Cl}^{-}$及 $\mathrm{SO}_{4}^{2-}$ 分别占 $37 \% \sim 75 \% 、 30 \% \sim 55 \%$ 和 $5 \% \sim 30 \% .4$ 个沉陷积水的主要阴离子相 同, 均为 $\mathrm{HCO}_{3}^{-}$和 $\mathrm{Cl}^{-}$. 综上所述, 4 个沉陷积水区水化学类型均为 $\mathrm{Cl}-\mathrm{Na} 、 \mathrm{HCO}_{3} \cdot \mathrm{Cl}-\mathrm{Na}$ 型, 水样点落在区域 $\mathrm{D}$ (氯化钠型) 和 $\mathrm{E}$ (混合型). 随沉陷时间的增加, 研究区水化学类型无明显变化, 同一沉陷时间内水化学也 无明显变化.

离子比例可进一步了解研究区离子来源及水化学演化过程.

(1) $\gamma\left(\mathrm{Na}^{+}+\mathrm{K}^{+}\right) / \gamma\left(\mathrm{Cl}^{-}\right)$

$\mathrm{Na}^{+}+\mathrm{K}^{+}$与 $\mathrm{Cl}^{-}$间的毫克当量比值可以反映积水中 $\mathrm{Na}^{+}+\mathrm{K}^{+}$与 $\mathrm{Cl}^{-}$的来源. 一般情况下, $\mathrm{Na}^{+}+\mathrm{K}^{+}$和 $\mathrm{Cl}^{-}$主要 来源于大气降水、蒸发岩溶解以及硅酸盐矿物风化 ${ }^{[19]}$. 当 $\gamma\left(\mathrm{Na}^{+}+\mathrm{K}^{+}\right) / \gamma\left(\mathrm{Cl}^{-}\right)=1$ 时, 蒸发岩溶解为 $\mathrm{Na}^{+}+\mathrm{K}^{+}$ 主要贡献源; 当 $\gamma\left(\mathrm{Na}^{+}+\mathrm{K}^{+}\right) / \gamma\left(\mathrm{Cl}^{-}\right)>1$ 时, $\mathrm{Na}^{+}$有其他来源, 有可能来源于硅酸盐矿物风化, 特别是在确定重 碳酸根是主要阴离子的前提下, 硅酸盐风化表达式如下:

$$
(\mathrm{Na}, \mathrm{K})_{2} \mathrm{Al}_{2} \mathrm{Si}_{6} \mathrm{O}_{6}+3 \mathrm{H}_{2} \mathrm{O}+2 \mathrm{CO}_{2} \rightarrow 2(\mathrm{Na}, \mathrm{K})^{+}+2 \mathrm{HCO}_{3}^{-}+\mathrm{H}_{4} \mathrm{Al}_{2} \mathrm{Si}_{6} \mathrm{O}_{6}+4 \mathrm{SiO}_{2}
$$

从图 3a 可看出研究区积水均分布在 $1: 1$ 线上方, 表明 4 个沉陷区积水中 $\mathrm{Na}^{+}$不仅来源于蒸发岩溶解, 还 来源于硅酸盐风化, 这与 $\mathrm{HCO}_{3}^{-}$在积水中浓度较高相符.

(2) $\gamma\left(\mathrm{Ca}^{2+}+\mathrm{Mg}^{2+}\right) / \gamma\left(\mathrm{HCO}_{3}^{-}\right)$

水体中 $\mathrm{Ca}^{2+} 、 \mathrm{Mg}^{2+}$ 通常来自含䥻、镁的硅酸盐和碳酸盐, $\mathrm{HCO}_{3}^{-}$一般来自碳酸盐或硅酸盐岩石. 将 $\gamma\left(\mathrm{Ca}^{2+}+\right.$ $\left.\mathrm{Mg}^{2+}\right)$ 值与 $\gamma\left(\mathrm{HCO}_{3}^{-}\right)$值进行比较, 可判断影响沉陷区积水化学成分的主导作用是碳酸盐岩溶解或是硅酸盐 风化. 当 $\gamma\left(\mathrm{Ca}^{2+}+\mathrm{Mg}^{2+}\right) / \gamma\left(\mathrm{HCO}_{3}^{-}\right)=1$ 时, 表明 $\mathrm{Ca}^{2+} 、 \mathrm{Mg}^{2+}$ 来源于碳酸盐岩溶解; 当 $\gamma\left(\mathrm{Ca}^{2+}+\mathrm{Mg}^{2+}\right) / \gamma\left(\mathrm{HCO}_{3}^{-}\right)<1$ 时, 反映 $\mathrm{Ca}^{2+} 、 \mathrm{Mg}^{2+}$ 主要受硅酸盐风化和蒸发岩溶解影响. 从图 $3 \mathrm{~b}$ 可以看出, 研究区积水除个别点外均分布 在 $1: 1$ 比例线下方, 表明积水中 $\mathrm{Ca}^{2+} 、 \mathrm{Mg}^{2+}$ 来源于硅酸盐风化和蒸发岩溶解, 这与上文 $\mathrm{Na}^{+}$的来源相符.

(3) $\gamma\left(\mathrm{Na}^{+}-\mathrm{Cl}^{-}\right) /\left(\gamma\left(\mathrm{Ca}^{2+}+\mathrm{Mg}^{2+}\right)-\gamma\left(\mathrm{SO}_{4}^{2-}+\mathrm{HCO}_{3}^{-}\right)\right)$

$\gamma\left(\mathrm{Na}^{+}-\mathrm{Cl}^{-}\right) /\left(\gamma\left(\mathrm{Ca}^{2+}+\mathrm{Mg}^{2+}\right)-\gamma\left(\mathrm{SO}_{4}^{2-}+\mathrm{HCO}_{3}^{-}\right)\right)$的比值可以反映水体是否发生了阳离子交替吸附作用. 若 $\gamma\left(\mathrm{Na}^{+}-\mathrm{Cl}^{-}\right)$与 $\left(\gamma\left(\mathrm{Ca}^{2+}+\mathrm{Mg}^{2+}\right)-\gamma\left(\mathrm{SO}_{4}^{2-}+\mathrm{HCO}_{3}^{-}\right)\right)$呈负相关, 斜率为 -1 , 黏土矿物中 $\mathrm{Ca}^{2+} 、 \mathrm{Mg}^{2+}$ 与水中 $\mathrm{Na}^{+}$ 发生交换增加了水中 $\mathrm{Na}^{+}$浓度, 表明水中发生了阳离子交替吸附作用, 表达式如下:

$$
\mathrm{Na}^{+}\left(\mathrm{K}^{+}\right)(\text {秥土 })+\mathrm{Ca}^{2+}\left(\mathrm{Mg}^{2+}\right)(\text { 水 }) \rightarrow \mathrm{Na}^{+}\left(\mathrm{K}^{+}\right)(\text {水 })+\mathrm{Ca}^{2+}\left(\mathrm{Mg}^{2+}\right)(\text { 黏土 })
$$

从图 3c 可看出, 顾桥、潘二、新庄孜和潘一矿沉陷积水的 $\gamma\left(\mathrm{Na}^{+}-\mathrm{Cl}^{-}\right)$与 $\gamma\left(\mathrm{Ca}^{2+}+\mathrm{Mg}^{2+}\right)-\gamma\left(\mathrm{SO}_{4}^{2-}+\mathrm{HCO}_{3}^{-}\right)$ 比值呈负相关, 斜率为 -0.95 , 接近 -1 , 表明积水发生了较为明显的阳离子交替吸附作用.
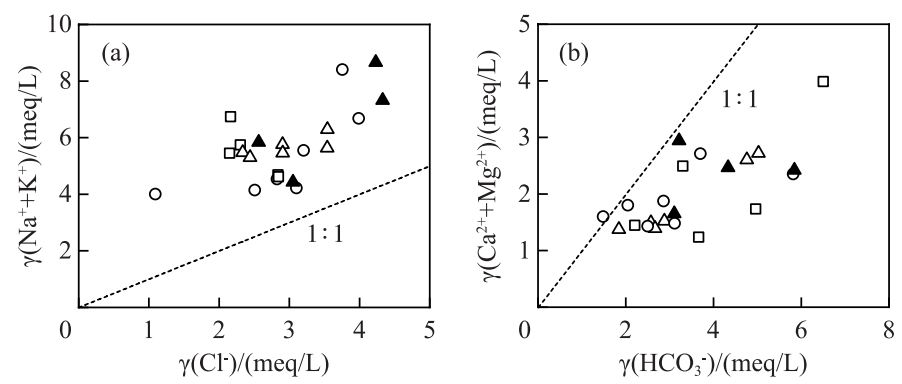

图 3 沉陷积水离子比例图

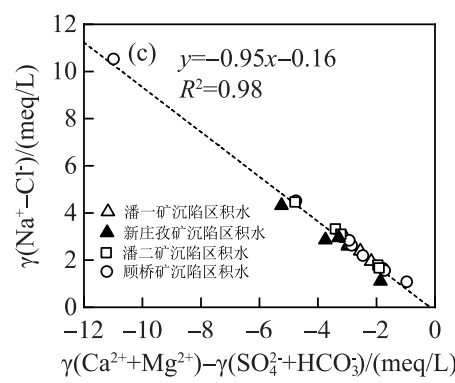

$\gamma\left(\mathrm{Ca}^{2+}+\mathrm{Mg}^{2+}\right)-\gamma\left(\mathrm{SO}_{4}^{2-}+\mathrm{HCO}_{3}^{-}\right) /(\mathrm{meq} / \mathrm{L})$

Fig.3 Ion ratio diagram of subsidence lake water

Gibbs 利用 TDS 与 $\rho\left(\mathrm{Na}^{+}\right) / \rho\left(\mathrm{Na}^{+}+\mathrm{Ca}^{2+}\right)$ 和 $\rho\left(\mathrm{Cl}^{-}\right) / \rho\left(\mathrm{Cl}^{-}+\mathrm{HCO}_{3}^{-}\right)$的比值关系, 根据世界范围内河流、湖 泊及主要海洋水分析, 提出了天然河水溶质起源模型 ${ }^{[20]}$. 该模型将河水离子起源的自然控制因素分为岩石 
风化型、大气降水控制型和蒸发-浓缩型. 自然条件下, 水样点落在模型内. 随着水化学研究的丰富和深人, 许多研究发现部分样点落在 Gibbs 图外, 离子起源可能受人为因素影响 ${ }^{[21-23]}$. 将顾桥、潘二、潘一及新庄孜矿 沉陷积水的水化学数据绘人 Gibbs 模型中, 如图 4 .

从图 4 可看出, 阴离子组分落在 Gibbs 图内,偏向蒸发作用区,受蒸发结晶作用控制. 阳离子组分部分落 在 Gibbs 图外,水化学离子组分受到外源输人及人为活动等外界环境的影响,这与采煤沉陷区周边复杂环境 有关. 首先, 人工沉陷区与天然湖泊相比, 人为活动更显著. 煤矿开采过程中产生大量煤矸石, 路基填筑材料 作为其资源化利用的重要途径之一, 被广泛采用. 其中顾桥矿沉陷区周边大量道路用煤矸石回填筑路, 潘 一、新庄孜及潘二沉陷区周边也存在这种现象. 矸石堆的淋滤液流人积水中, 导致积水的离子组成发生改变. 其次, 受采煤沉陷的影响, 目前大小不一的沉陷湿地都是由原来的农田转变而来. 沉陷湿地相比自然湿地和 积水前的农田生态系统, 土壤结构和理化性质发生变化, 微生物、微量营养元素及有机质附存状态发生改 变, 从土壤进人水中, 影响积水的水化学性质. 同时,农药、有机肥及农用地膜的施用,持久性污染物不易被 生物降解导致其在农田土壤中长期留存从而进人水体, 这些因素都会导致沉陷区积水中阳离子组成偏离天 然水体背景值. 最后, 沉陷区人工水产养殖活动密集. 两淮地区有大面积的沉陷水域, 当地居民因地制宜, 发 展渔业养殖活动. 鱼饲料中含有丰富的营养物质, 投人水中也会影响积水初始离子化学组成.
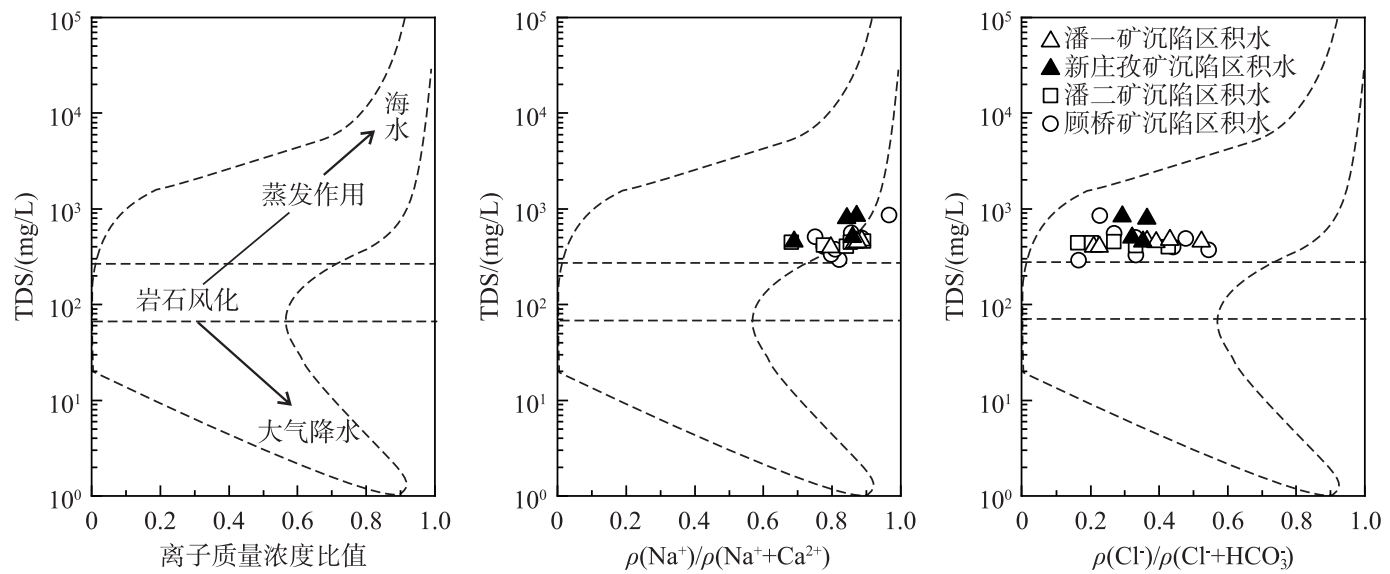

图 4 沉陷积水 Gibbs 图

Fig.4 Gibbs diagram of subsidence lake water

\section{2 水体氢氧稳定同位素分布特征}

3.2.1 大气降水同位素特征 从源区蒸发水蒸气到降雨 区途中水蒸气冷凝过程中会导致氢氧稳定同位素组成 按一定线性关系变化, 这种关系称为大气降水线方程. $\delta \mathrm{D}$ 和 $\delta^{18} \mathrm{O}$ 间比例关系的研究,对揭示水汽来源及反映 某一地区的自然地理环境有重要意义.

经过降雨量加权计算, 淮南大气降水 $\delta \mathrm{D}-\delta^{18} \mathrm{O}$ 关 系如图 5 所示, 氢氧稳定同位素值变化幅度较大: $\delta \mathrm{D}$ 的 变化范围为 $-135.91 \% 0 \sim-6.04 \% 0, \delta^{18} \mathrm{O}$ 的变化范围为 $-17.34 \%$ $-2.03 \%$. 根据 $\delta \mathrm{D}$ 和 $\delta^{18} \mathrm{O}$ 数据, 采用最小二 乘法回归拟合得淮南大气降水线方程: $\delta \mathrm{D}=8.85 \delta^{18} \mathrm{O}+$ $18.73\left(R^{2}=0.98\right)$, 与南京、鹰潭、翻阳湖、绍兴等地相似 (表 2), 斜率和截距均略大于全球大气降水线 (GMWL: $\left.\delta \mathrm{D}=8 \delta^{18} \mathrm{O}+10\right)^{[24]}$ 和中国大气降水线 (LMWL: $\delta \mathrm{D}=$

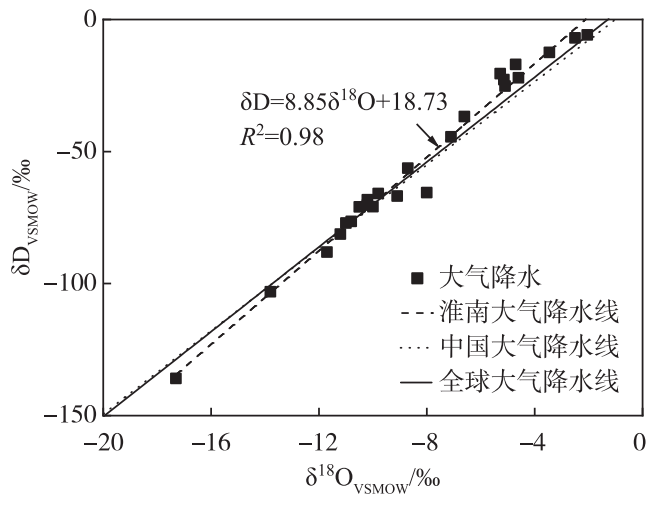

图 5 研究区大气降水 $\delta D-\delta^{18} O$ 关系图

Fig.5 Relationship between $\delta \mathrm{D}-\delta^{18} \mathrm{O}$ of atmospheric precipitation in the study area 
$\left.7.9 \delta^{18} \mathrm{O}+8.2\right)^{[25]}$. 各地区由于地理位置、自然环境及降水环境的差异, 大气降水线也不相同. 一般来说, 在气候 干燥地区, 雨滴在下落过程中会发生二次蒸发从而导致斜率和截距偏低,气候越干热, 大气降水线的斜率和截 距也越小, 湿润多雨区域相反 ${ }^{[26]}$. 这反映出淮南地区气候相对湿润, 水体蒸发作用比全国平均蒸发水平弱.

表 2 不同地区大气降水线

Tab.2 Atmospheric precipitation lines in different regions

\begin{tabular}{cccc}
\hline 地区 & 大气降水线方程 & 相关系数 $r$ & 参考文献 \\
\hline 南京 & $\delta \mathrm{D}=8.49 \delta^{18} \mathrm{O}+17.69$ & 0.91 & {$[27]$} \\
鹰潭 & $\delta \mathrm{D}=8.61 \delta^{18} \mathrm{O}+18.34$ & 0.98 & {$[28]$} \\
鄱阳湖 & $\delta \mathrm{D}=8.99 \delta^{18} \mathrm{O}+11.52$ & 0.94 & {$[29]$} \\
绍兴 & $\delta \mathrm{D}=8.36 \delta^{18} \mathrm{O}+14.92$ & 0.97 & {$[30]$} \\
上海 & $\delta \mathrm{D}=8.10 \delta^{18} \mathrm{O}+10.44$ & 0.96 & {$[31]$} \\
淮南 & $\delta \mathrm{D}=8.85 \delta^{18} \mathrm{O}+18.73$ & 0.98 & 本研究 \\
\hline
\end{tabular}

3.2 .2 沉陷区积水同位素特征 图 6 为沉陷区积水氢氧稳定同位素含量分布图,顾桥矿沉陷积水 $\delta^{18} \mathrm{O}$ 的范 围为 $-2.73 \% 0 \sim-1.71 \% 0, \delta \mathrm{D}$ 的范围为 $-24.20 \% 0 \sim-17.02 \%$, 均值分别为 $-2.20 \% 0$ 和 $-20.48 \%$, 潘二矿沉陷区积 水 $\delta^{18} \mathrm{O}$ 的范围为 $-5.34 \% 0 \sim-3.12 \% 0, \delta \mathrm{D}$ 的范围为 $-43.33 \% 0 \sim-26.14 \%$, 均值分别为 $-4.56 \% 0$ 和 $-36.62 \% 0$; 新庄 孜矿沉陷区积水 $\delta^{18} \mathrm{O}$ 的范围为 $-7.43 \%$ - 6.71\%,$\delta \mathrm{D}$ 的范围为 $-53.16 \% 0 \sim-52.00 \%$, 均值分别为 $-6.95 \% 0$ 和 $-53.00 \%$; 潘一矿沉陷区积水 $\delta^{18} \mathrm{O}$ 的范围为 $-7.61 \% 0 \sim-5.94 \%, \delta \mathrm{D}$ 的范围为 $-58.10 \%$ $-44.04 \%$, 均值分别 为 $-6.53 \% 0$ 和 $-49.83 \%$. 4 个沉陷区的样点都落在当地大气降水线附近, 表明沉陷区积水主要来源于大气降 水. 同时, 4 个沉陷区积水均与各自周边的浅层地下水同位素值较为接近, 表明浅层地下水也可能是沉陷积 水的来源之一. 为了获得水源水的原始同位素组成, 通过沿着假定的蒸发线将单个蒸发样本转换回 LMWL 来获得对平均水源水的合理估计, 从而得到蒸发前成分的估计, 然后取其平均值 ${ }^{[32-33]}$. 最终获得研究区地表 水蒸发线方程为 $\delta \mathrm{D}=4.73 \delta^{18} \mathrm{O}-13.80$, 斜率小于 LMWL 的斜率, 表明沉陷区积水受到了一定的蒸发作用.

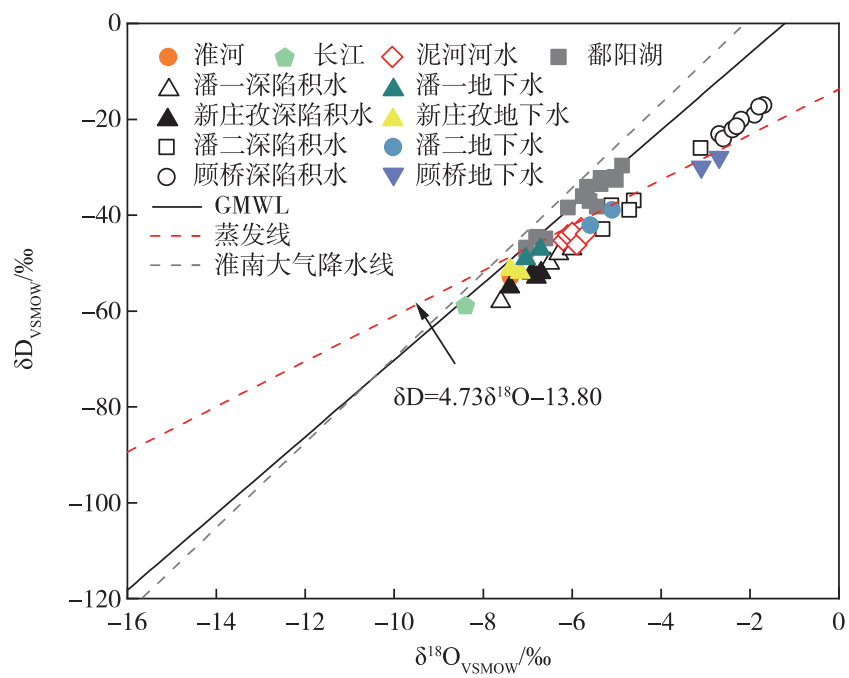

图 6 沉陷区不同水体 $\delta \mathrm{D}-\delta^{18} \mathrm{O}$ 关系图

Fig. $6 \delta \mathrm{D}-\delta^{18} \mathrm{O}$ relationship diagram of different water in subsidence area

氛盈余 $(d)$ 值是蒸发效应对地表水物理化学性质的另一参考指数, 主要受空气相对湿度控制, 蒸发作用 越强, $d$ 值越偏负 ${ }^{[34]}$. 由表 1 可知, 研究区顾桥沉陷积水 $d$ 值范围为 $-3.82 \% 0 \sim-1.44 \%$, 潘二沉陷积水 $d$ 值范 围为 $-1.40 \% 0 \sim 2.81 \%$, 新庄孜沉陷积水 $d$ 值范围为 $1.41 \% 0 \sim 3.12 \%$, 潘一沉陷积水 $d$ 值范围为 $1.04 \% 0 \sim$ 
$3.22 \%$. 由此可见, 顾桥沉陷积水 $d$ 值最偏负, 受强烈蒸发作用影响, 潘二沉陷积水受蒸发影响次之, 新庄孜 和潘一沉陷积水受蒸发影响最小. 蒸发作用增强, 积水蒸发过程中较轻的水分子会优先从液态水中向气态 水中逸出, $\mathrm{D}$ 和 ${ }^{18} \mathrm{O}$ 在液态水中积累, 这使得液态水中同位素富集, 重同位素留存比例增大. 因此, 随沉陷时 间增加,积水中重同位素越贫化,同一沉陷时间不同类型的积水同位素值变化较小.

本研究比较了沉陷积水与淮河、长江水体同位素值的差异. 同处于亚热带季风气候区,沉陷区积水与淮 河 ${ }^{[35]} 、$ 长江 ${ }^{[36]}$ 水体相比同位素值相对偏高, 这可能是由于不同水体的混合、蒸发和人类活动等因素的影响. 沉陷区积水相对于长江、淮河等天然大型河流自然, 水体流动性小, 混合程度低, 径流速度较慢, 小范围内受 沿岸人类活动影响小. 长江、淮河径流更新速度快, 干流受支流的汇人, 还存在水库大坝储存, 这些因素会导 致河流的自然流动状态发生改变,同位素值不断发生变化.

同时,本文还比较了沉陷积水与天然大型湖泊鄱阳湖 ${ }^{[37]}$ 之间的氢氧稳定同位素特征. 从图 6 可看出, 鄱 阳湖湖水同位素值分布在大气降水线附近, 表明水体主要来源于大气降水. 由于鄱阳湖水来自 “五河” (饶 河、信江、抚河、赣江、修水) 水的共同汇人, 河水在湖泊中发生混合, 受各条河流的综合影响, 湖水同位素没 有表现出明显的空间差异性,同位素差异分馏不明显. 积水由于采煤沉陷时间不一致,形成时间不同,各沉 陷积水区相对分散分布,导致其同位素分馏存在差异性.

3.2 .3 不同沉陷时间沉陷区积水同位素特征顾桥 矿、潘二矿、新庄孜矿/潘一矿沉陷区的沉陷时间不 同, 分别为 $10 \sim 20 、 20 \sim 30$ 及 $30 \sim 40 \mathrm{a}$, 对应的沉陷积 水中氢氧稳定同位素值也存在差异. 其中 $30 \sim 40 \mathrm{a}$ 的沉陷积水中潘一矿积水区与泥河有水力联系是开 放型水域,新庄孜矿积水区是封闭型水域. 由图 7 可 看出, 当沉陷类型相同时, 随着时间的增加, 积水中 重同位素越来越贫化; 当沉陷时间相同时,不同类型 积水同位素值变化较小.

分析其原因有:1) 降水补给稀释的影响. 前文已 经表明,积水主要来源为大气降水, 积水同位素值与 补给来源有关.气象监测资料表明, 研究区处于湿润 季风区, 年平均降雨量为 $926 \mathrm{~mm} .1980$ 年以来, 淮南 降雨量整体呈缓慢上升趋势, 其中 2002-2010 年经 历过多雨期. 在局部地理因子中, 影响降水同位素的

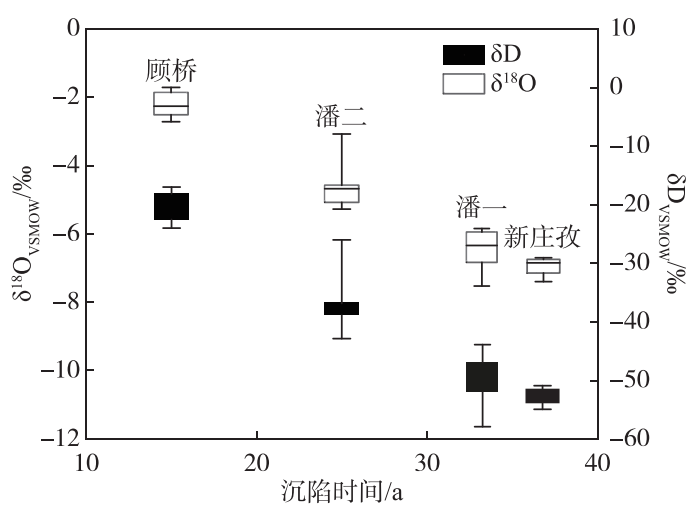

图 7 不同沉陷年限积水同位素组成

Fig.7 Isotopic composition of subsidence lake water in different years

主导效应分别是雨量效应和温度效应 ${ }^{[38]}$. 小降水事件中同位素的组成主要受温度控制, 大降水事件中同位 素的组成主要受降雨量控制. 这是因为在持续性大降雨条件下,水气压逐渐升高直至饱和, 雨滴因二次蒸发 造成的消耗减小, 同时空气相对湿度较高, 易发生同位素稀释效应 (较高的相对湿度使同位素交换反应更 快). 此外, 在降雨过程中雨水除受云下二次蒸发作用外, 还存在地表水在降水过程中的蒸发贡献. 一方面, 轻同位素分子进人云层上层, 使云层中氢和氧重同位素的含量相对较低. 另一方面, 在雨滴形成的过程中, 雨滴与空气中的水蒸气 ( 以 ${ }^{18} \mathrm{O}$ 为例) 之间发生的同位素交换反应如下:

$$
{ }^{18} \mathrm{O}_{\text {水 }}+{ }^{16} \mathrm{O}_{\text {乞 }} \rightarrow{ }^{16} \mathrm{O}_{\text {水 }}+{ }^{18} \mathrm{O}_{\text {乞 }}
$$

由于这种反应, 雨滴中重同位素贫化 ${ }^{[39]}$, 导致降水补给积水后产生稀释作用. 新庄孜矿和潘一矿沉陷 区积水经过 30 余年降雨的混合补给, 水中同位素发生长时间的稀释, 同位素值最低. 顾桥矿沉陷区则相反, 由于其沉陷时间相对较短, 积水稀释程度低, 同位素值相对偏高.

2) 水体蒸发及河流补给的影响. 在水的蒸发过程中, 氢同位素和氧同位素的分馏最初发生在水气界面 的边界层中. 水分子在液相中的氢键破裂后蒸发, 在液相表面直接形成一层饱和水汽,这一饱和水汽层与液 态水相形成同位素平衡 ${ }^{[40]}$. 处于平衡状态的蒸发水体, 液汽相之间的平衡始终维持在水一水汽界面, 水域面 积越大, 水体与空气接触面积越大, 当平衡被瞬间打破时, 蒸发的水汽从液体中逃逸的更多. 所以受蒸发作 用影响的水域面积越大, 水体蒸发作用越显著 ${ }^{[41]}$, 氢氧稳定同位素越富集. 顾桥、潘二及新庄孜矿沉陷区的 
同位素值与其面积大小符合,沉陷面积最大的顾桥矿积水区重同位素最富集, 面积最小的新庄孜矿积水区 重同位素最贫化. 这反映出随沉陷时间的增加,积水中重同位素越来越贫化. 从图 7 可看出,对于沉陷时间 同为 30 40 a 的封闭型沉陷区 (新庄孜) 和开放型沉陷区 (潘一), 两者同位素值变化较小. 这可能由于泥河 在沉陷积水区停留时间短, 与积水没有发生充分混合, 大部分水体同位素值保留沉陷积水本身特征值, 与新 庄孜沉陷积水同位素值差异不大. 因此, 在河水与沉陷积水没有发生充分混合的情况下, 积水同位素值受河 水影响范围较小,长期的沉陷时间对积水同位素值的影响可能更显著.

3) 浅层地下水补给的影响. 采煤造成地面沉陷后, 在沉降量较大区域积水成湖. 由于研究区浅层地下水 埋深较小, 一般 1 3 m, 在积水过程中浅层地下水可能会逐渐渗出补给沉陷积水. 图 6 中不同沉陷积水与其 对应的周边浅层地下水的 $\delta \mathrm{D}$ 和 $\delta^{18} \mathrm{O}$ 值较为接近, 表明积水同位素值的差异受到浅层地下水补给的影响.

\section{4 结论}

1) 研究区积水中 $\mathrm{Na}^{+}$为优势阳离子, $\mathrm{HCO}_{3}^{-}$和 $\mathrm{Cl}^{-}$为优势阴离子, 水化学类型均为 $\mathrm{HCO}_{3} \cdot \mathrm{Cl}-\mathrm{Na}$ 和 $\mathrm{Cl}-\mathrm{Na}$ 型; 不同沉陷时间和类型的积水水化学类型无明显变化. 积水中常量离子主要来源蒸发岩溶解和硅酸盐风 化,也发生阳离子吸附交替作用,受蒸发作用和人为活动的影响明显.

2) 研究区大气降水线斜率和截距均大于 GMWL 和 LMWL, 反映出淮南地区气候相对湿润. 不同年限沉 陷区积水氢氧同位素样点在淮南大气降水线右下方依次分布并接近降水线, 表明沉陷积水主要来源于大气 降水.

3) 受降水稀释、水体蒸发及地下水补给的影响, 随沉陷年限的增加积水中重同位素逐渐贫化, 同一沉陷 年限不同类型的积水同位素值变化较小. 在河水与积水混合不充分的条件下, 积水同位素值受河水影响范 围较小, 长时间的沉陷时间对积水同位素值的影响可能更显著.

本文基于现有数据和资料, 探讨了不同年限及类型的沉陷区积水氢氧稳定同位素组成分布特征及其可 能的原因. 关于沉陷积水同位素差异分馏形成机理及其指示的积水来源与组成等问题还无法得到定量化解 释,需更多的观测数据和资料做进一步的研究.

\section{5 参考文献}

[ 1 ] Wu XQ, Zhou DW, An SK et al. Evolvement trend of land and water systems in Huainan Panxie mining area and its countermeasures. Journal of China Coal Society, 2015, 40(12): 2927-2932. [吴雪茜, 周大伟, 安士凯等. 淮南潘谢矿区 土地与水域演变趋势及治理对策. 煤炭学报, 2015, 40(12): 2927-2932.]

[ 2 ] Chen YC, Yuan L, Xu C. Investigation on using mining subsidence area to build a reservoir in Huainan Coal Mining Area. Journal of China Coal Society, 2016, 41(11): 2830-2835. [陈永春, 袁亮, 徐羽. 淮南矿区利用采煤塌陷区建设平 原水库研究. 煤炭学报, 2016, 41(11): 2830-2835.]

[ 3 ] Fu YH, Hu ZQ, Xiao W et al. Subsidence wetlands in coal mining areas with high water level and their ecological restoration. Wetland Science, 2016, 14(5): 671-676. [付艳华, 胡振琪, 肖武等. 高潜水位煤矿区采煤沉陷湿地及其生态 治理. 湿地科学, 2016, 14(5): 671-676.

[ 4 ] Zheng LG, Chen X, Dong XL et al. Using $\delta^{34}{\mathrm{~S}-\mathrm{SO}_{4}}_{4}$ and $\delta^{18} \mathrm{O}-\mathrm{SO}_{4}$ to trace the sources of sulfate in different types of surface water from the Linhuan coal-mining subsidence area of Huaibei, China. Ecotoxicology and Environmental Safety, 2019, 181: 231-240. DOI: 10.1016/j.ecoenv.2019.06.001.

[ 5 ] Wang TT, Yi QT, Hu YB et al. Eutrophication and nutrient enrichment bioassays in the waters of the Huainan and Huaibei coal mining subsidence areas, Anhui Province. J Lake Sci, 2013, 25(6) : 916-926. DOI: 10.18307/2013.0616. [王婷 婷, 易齐涛, 胡友彪等. 两淮采煤沉陷区水域水体富营养化及氮、磷限制模拟实验. 湖泊科学, 2013, 25 (6): 916-926.]

[ 6 ] Kong LJ, Jiang CL, Zheng LG et al. Characters of hydrochemistry and their influenced factors of different waters in the Linhuan coal mining subsidence area of Huaibei City. J Lake Sci, 2017, 29(5) : 1158-1167. DOI: 10.18307/2017.0513. [孔令健, 姜春露, 郑刘根等. 淮北临涣矿采煤沉陷区不同水体水化学特征及其影响因素. 湖泊科学, 2017,29 (5) : 1158-1167.]

[ 7 ] Sun PF, Yi QT, Xu GQ. Characteristics of water chemistry and their influencing factors in subsidence waters in the Huain- 
an and Huaibei mining areas, Anhui Province. Journal of China Coal Society, 2014, 39(7) : 1345-1353. [孙鹏飞, 易齐 涛, 许光泉. 两淮采煤沉陷积水区水体水化学特征及影响因素. 煤炭学报, 2014, 39(7) : 1345-1353.]

[ 8 ] Yang J, Dudley BD, Montgomery K et al. Characterizing spatial and temporal variation in ${ }^{18} \mathrm{O}$ and ${ }^{2} \mathrm{H}$ content of New Zealand river water for better understanding of hydrologic processes. Hydrological Processes, 2020, 34(26) : 5474-5488. DOI: 10.1002/hyp.13962.

[ 9 ] Halder J, Decrouy L, Vennemann TW. Mixing of Rhône River water in Lake Geneva (Switzerland-France) inferred from stable hydrogen and oxygen isotope profiles. Journal of Hydrology, 2013, 477: 152-164. DOI: 10.1016/j.jhydrol.2012. 11.026 .

[10] Qian H, Wu JH, Zhou YH et al. Stable oxygen and hydrogen isotopes as indicators of lake water recharge and evaporation in the lakes of the Yinchuan Plain. Hydrological Processes, 2014, 28(10) : 3554-3562. DOI: 10.1002/hyp.9915.

[11] Zannoni D, Steen-Larsen HC, Rampazzo G et al. The atmospheric water cycle of a coastal lagoon: An isotope study of the interactions between water vapor, precipitation and surface waters. Journal of Hydrology, 2019, 572: 630-644. DOI: 10. 1016/j.jhydrol.2019.03.033.

[12] Wang BL, Zhang HT, Liang X et al. Cumulative effects of cascade dams on river water cycle: Evidence from hydrogen and oxygen isotopes. Journal of Hydrology, 2019, 568: 604-610. DOI: 10.1016/j.jhydrol.2018.11.016.

[13] Zhang L, Qin XG, Liu JQ et al. Characters of hydrogen and oxygen stable isotope of different water bodies in Huainan coal mining area. Journal of Jilin University: Earth Science Edition, 2015, 45(5): 1502-1514. [张否, 秦小光, 刘嘉麒等. 淮南采煤沉陷区积水来源的氢氧稳定同位素证据. 吉林大学学报: 地球科学版, 2015, 45(5): 1502-1514.]

[14] Ge T, Chu TT, Liu GJ et al. Characterisics of hydrogen and oxygen isotopes of deep ground water in the Panxie mining area in Huainan Coal field. Journal of University of Science and Technology of China, 2014, 44(2) : 112-118,170. [葛涛, 储婷婷, 刘桂建等. 淮南煤田潘谢矿区深层地下水氢氧同位素特征分析. 中国科学技术大学学报, 2014, 44(2): 112-118,170.]

[15] Zhang L, Yi QT, Li H et al. Water quality and water environmental capacity for the small subsidence lakes in the Huainan and Huaibei coal mine areas, Anhui Province. Chinese Journal of Ecology, 2015, 34(4) : 1121-1128. DOI: 10.13292/j. 1000-4890.20150311.028. [章否, 易齐涛, 李慧等. 两淮矿区小型塌陷湖泊水质特征与水环境容量. 生态学杂志, 2015, 34(4) : 1121-1128.]

[16] Zhang WX. Water quality characteristics and changing trend of coal mining subsidence area with high phreatic level in Huainan[Dissertation]. Hefei: Anhui University, 2019. [张维翔. 淮南高潜水位采煤沉陷区水质特征及变化趋势 [ 学 位论文]. 合肥: 安徽大学, 2019.]

[17] Gonfiantini R. Standards for stable isotope measurements in natural compounds. Nature, 1978, 271 (5645) : $534-536$. DOI: $10.1038 / 271534 \mathrm{a} 0$.

[18] Li QY, Wu JL, Shen BB et al. Water chemistry and stable isotopes of different water types in Tajikistan. Environmental Processes, 2018, 5(1) : 127-137. DOI: 10.1007/s40710-018-0312-9.

[19] Li ZK, Xia MH, Dong SG et al. Hydrochemical characteristics and evolution characteristics of shallow groundwater in the Luoyang basin. Earth and Environment, 2019, 47(1): 57-63. [李政葵, 夏曼宏, 董少刚等. 洛阳盆地浅层地下水化 学特征及其演化特征分析. 地球与环境, 2019, 47(1): 57-63.]

[20] Gibbs RJ. Mechanisms controlling world water chemistry. Science, 1970, 170(3962) : 1088-1090. DOI: 10.1126/science. 170.3962.1088.

[21] Kou YC, Hua K, Li Z et al. Major ionic features and their possible controls in the surface water and groundwater of the Jinghe river. Environmental Science, 2018, 39(7) : 3142-3149. DOI: 10.13227/j.hjkx.201710202. [寇永朝, 华琨, 李 洲等. 泾河支流地表水地下水的水化学特征及其控制因素. 环境科学, 2018, 39(7): 3142-3149.]

[22] Tang XW, Wu JK, Xue LY et al. Major ion chemistry of surface water in the Xilin river basin and the possible controls. Environmental Science, 2014, 35(1) : 131-142. DOI: 10.13227/j.hjkx.2014.01.065. [唐笚雯, 吴锦奎, 薛丽洋等. 锡 林河流域地表水水化学主离子特征及控制因素. 环境科学, 2014, 35(1): 131-142.]

[23] Han ZM, Jia KL, Sun B et al. Component characteristics and sources of ions in surface water and groundwater of Hulun lake basin. Ecology and Environmental Sciences, 2018, 27(4): 744-751. [韩知明, 贾克力, 孙标等. 呼伦湖流域地表 水与地下水离子组成特征及来源分析. 生态环境学报, 2018, 27(4) : 744-751.]

[24] Craig H. Isotopic variations in meteoric waters. Science, 1961, 133 (3465) : 1702-1703. DOI: 10.1126/science. 133. 3465.1702 . 
[25] Zheng SH, Hou FG, Ni BL. A study on stable hydrogen and oxygen isotopes of atmospheric precipitation in my coconut. Chinese Science Bulletin, 1983, 28(13) : 801-806. [郑淑㯖, 侯发高, 倪葆龄. 我国大气降水的氢氧稳定同位素研 究. 科学通报, 1983, 28(13): 801-806.]

[26] Liu JY, Zhang FP, Feng Q et al. Influence of below-cloud secondary evaporation on stable isotope composition in precipitation in Northwest China. Chinese Journal of Applied Ecology, 2018, 29(5) : 1479-1488. DOI: 10.13287/j.1001-9332. 201805.028. [刘洁遥, 张福平, 冯起等. 西北地区降水稳定同位素的云下二次蒸发效应. 应用生态学报, 2018,29 (5) : 1479-1488. ]

[27] Wang T, Zhang JR, Liu X et al. Variations of stable isotopes in precipitation and water vapor sources in Nanjing area. Journal of China Hydrology, 2013, 33(4) : 25-31. [王涛, 张洁茹, 刘笑等. 南京大气降水氧同位素变化及水汽来源 分析. 水文, 2013, 33(4): 25-31.]

[28] Shen YJ, Peng XH. Stable isotopes of hydrogen and oxygen in the precipitation of Yingtan. Ecology and Environmental Sciences, 2014, 23(1) : 101-105. [沈业杰, 彭新华. 鹰潭地区大气降水中氢氧稳定同位素特征研究. 生态环境学报, $2014,23(1): 101-105$. ]

[29] Zhao HP, Zhang X, Deng ZM et al. Analysis of stable hydrogen and oxygen isotope characteristics of precipitation in Poyang Lake wetland. Water Resources Research, 2015, (4) : 257-264. DOI: 10.12677/JWRR.2015.43031. [ 赵惠萍, 张 翔, 邓志民等. 鄱阳湖湿地降水氢氧稳定同位素特征分析. 水资源研究, 2015，(4)：257-264.]

[30] Ma YB, Xu Q, Gao DQ et al. Composition of hydrogen and oxygen isotope in precipitation and source apportionment of water vapor in the wetland forest area of tangpu reservoir, Zhejiang Province. Forest Research, 2018, 31(3) : 37-44. [马迎 宾, 徐庆, 高德强等. 汤浦水库湿地森林区大气降水氢氧同位素特征及水汽来源. 林业科学研究, 2018, 31(3): 37-44.]

[31] Zhang L, Zhu ZP, Yang Y et al. Characteristics of hydrogen and oxygen isotope of precipitation and its environmental significance in Shanghai. Earth and Environment, 2020, 48(1): 120-128. [张峦, 朱志鹏, 杨言等. 上海地区大气降水 中氢氧同位素特征及其环境意义. 地球与环境, 2020, 48(1) : 120-128.]

[32] Benettin P, Volkmann THM, von Freyberg J et al. Effects of climatic seasonality on the isotopic composition of evaporating soil waters. Hydrology and Earth System Sciences, 2018, 22(5) : 2881-2890. DOI: 10.5194/hess-22-2881-2018.

[33] Shi PJ, Huang YN, Ji WJ et al. Impacts of deep-rooted fruit trees on recharge of deep soil water using stable and radioactive isotopes. Agricultural and Forest Meteorology, 2021, 300: 108325. DOI: 10.1016/j.agrformet.2021.108325.

[34 ] Han DM, Song XF, Currell MJ et al. A survey of groundwater levels and hydrogeochemistry in irrigated fields in the Karamay Agricultural Development Area, northwest China: Implications for soil and groundwater salinity resulting from surface water transfer for irrigation. Journal of Hydrology, 2011, 405(3/4) : 217-234. DOI: 10.1016/j.jhydrol.2011.03.052.

[35] Zhang L, Yuan RQ, Song XF et al. Spatial variation of stable isotopic composition in surface waters of the Huai River basin, China and the regional hydrological implication. Hydrology Research, 2018, 49(5) : 1452-1466. DOI: 10.2166/nh. 2017.027.

[36] Li J, Wu HW, Zhou YQ et al. Variations of stable oxygen and deuterium isotopes in river and lake waters during flooding season along the middle and lower reaches of the Yangtze River regions. Environmental Science, 2020, 41(3) : 1176-1183. DOI : 10.13227/j.hjkx.201908160. [李静, 吴华武, 周永强等. 长江中下游地区丰水期河、湖水氢氧同位素组成特 征. 环境科学, 2020, 41(3): 1176-1183.]

[37] Zhan LC, Chen JS, Huang DW et al. Stable isotope characteristics in the Poyang Lake region at Jiujiang section of the Yangtze River in different seasons. Journal of Hydraulic Engineering, 2016, 47(11): 1380-1388. [詹泸成, 陈建生, 黄 德文等. 长江干流九江段与鄱阳湖不同季节的同位素特征. 水利学报, 2016, 47(11): 1380-1388.]

[38] Stumpp C, Klaus J, Stichler W. Analysis of long-term stable isotopic composition in German precipitation. Journal of Hydrology, 2014, 517: 351-361. DOI: 10.1016/j.jhydrol.2014.05.034.

[39] Yang QC, Mu HK, Guo JC et al. Temperature and rainfall amount effects on hydrogen and oxygen stable isotope in precipitation. Quaternary International, 2019, 519: 25-31. DOI: 10.1016/j.quaint.2019.01.027.

[40] Gonfiantini R, Wassenaar LI, Araguas-Araguas L et al. A unified Craig-Gordon isotope model of stable hydrogen and oxygen isotope fractionation during fresh or saltwater evaporation. Geochimica et Cosmochimica Acta, 2018, 235: 224-236. DOI: $10.1016 /$ j.gca.2018.05.020.

[41] Chen XM, Gan YQ, Liu YD et al. Spatial distribution characteristics of hydrogen and oxygen isotopes in the mainstream of Yangtze River. Geological Science and Technology Information, 2011, 30(5) : 110-114. [ 陈新明, 甘义群, 刘运德等. 长江干流水体氢氧同位素空间分布特征. 地质科技情报, 2011, 30(5): 110-114.] 